\title{
The association of blood transfusion and acute kidney injury in diabetic coronary artery bypass grafting patients
}

\author{
Abdulkerim Özhan (D, Engin Akgül (D), Ali İhsan Parlar (D), Ahmet Çekirdekçi (D) \\ Department of Cardiovascular Surgery, Kütahya Health Sciences University, Evliya Çelebi Training and Research Hospital, Kütahya, Turkey
}

Received: January 29, 2021 Accepted: February 25, 2021 Published online: March 29, 2021

\begin{abstract}
Objectives: This study aims to investigate the association between blood transfusion and acute kidney injury (AKI) in diabetic coronary artery bypass grafting (CABG) patients.

Patients and methods: Between October 2016 and September 2019, a total of 270 elective CABG patients with diabetes (62 males, 208 females; mean age: $63.2 \pm 9.3$ years; range, 40 to 86 years) were retrospectively analyzed. The patients were divided into two groups according to presence of cardiac surgery-related AKI. Risk factors were compared between the groups.

Results: No significant difference was found between the groups in terms of baseline characteristics, except for body mass index, EuroSCORE II, and platelet count. The significant factors in the univariate analysis were included in the logistic regression. Only blood transfusion was found to be associated with AKI with red blood cell, fresh frozen plasma, platelet, and complete transfusions $(\mathrm{p}<0.001, \mathrm{p}<0.001, \mathrm{p}=0.002$, and $\mathrm{p}<0.001$, respectively).

Conclusion: Our study results suggest that perioperative red blood cell, fresh frozen plasma, platelet, and complete transfusions are associated with postoperative AKI in diabetic CABG patients.
\end{abstract}

Keywords: Acute kidney injury, blood transfusion, coronary artery bypass grafting, diabetes mellitus.

Coronary artery bypass grafting (CABG) is safely performed with low mortality and morbidity rates thanks to the increased surgical experience in recent years. Despite the increase in surgical experience, CABG may demand additional medical requirements that bring along inevitable complications. Blood transfusions are one of the most common requirements accompanying CABG and may result in undesirable side effects, such as acute kidney injury (AKI) ${ }^{[1]}$

Blood transfusion is frequently required after cardiac operations and the causes for transfusion requirement are several. Surgical bleeding during both the intra- and postoperative periods is very common in CABG patients. ${ }^{[2]}$ Antiaggregant and/or anticoagulant medications are frequently used during the perioperative period. The use of a cardiopulmonary bypass may lead to coagulopathy as a result of platelet dysfunction and a deteriorated coagulation cascade. Fluid replacement, particularly with crystalloids to provide hemodynamic stability, may cause dilutional anemia. All these factors play a role in the need for blood transfusion after CABG surgery. ${ }^{[3,4]}$
Blood transfusions are associated with AKI in CABG patients. ${ }^{[5,6]}$ Meanwhile, anemia itself has been shown as another cause of AKI. ${ }^{[7]}$ Maintaining a balance is important not to cause anemia, while also avoiding an unnecessary blood transfusion.

Patients undergoing CABG surgery have a high rate of diabetes mellitus. Diabetes mellitus increases the complication rates associated with AKI, impaired wound healing, and mortality. ${ }^{[8,9]}$ As diabetic patients are more susceptible to postoperative complications, special implementations with these patients may provide better outcomes after CABG. This is why we

Corresponding author: Abdulkerim Özhan, MD. Kütahya Sağllk Bilimleri Üniversitesi, Evliya Çelebi Eğitim ve Araştırma Hastanesi, Kalp ve Damar Cerrahisi Kliniği, 43040 Kütahya, Türkiye.

Tel: +90 274 - 2316660 e-mail: draozhan@gmail.com

\section{Citation:}

Özhan A, Akgül E, Parlar Aİ, Çekirdekçi A. The association of blood transfusion and acute kidney injury in diabetic coronary artery bypass grafting patients. Cardiovasc Surg Int 2021;8(1):13-19. 
have given a special interest in investigating the group of diabetic patients.

In this study, we aimed to investigate the risk factors, particularly blood transfusions in diabetic CABG patients, associated with AKI.

\section{PATIENTS AND METHODS}

The single-center, retrospective study was conducted at Kütahya Health Sciences University, Evliya Çelebi Training and Research Hospital, Department of Cardiovascular Surgery between October 2016 and September 2019. A total of 270 elective CABG patients with diabetes $(62$ males, 208 females; mean age: $63.2 \pm 9.3$ years; range, 40 to 86 years) who were followed up to two weeks until discharge were included in the study. All patients included in the study were elective CABG patients, all of whom had normal regulation of blood glucose at least one week before surgery to eliminate the negative effects of uncontrolled blood glucose. Patients with emergency CABG surgery, off-pump surgery, simultaneous operations with $\mathrm{CABG}$, cardiac reoperations, preoperative renal impairments, and in-hospital mortality were excluded from the study to standardize the results and avoid potential pre-existing negative impacts on renal function. All patients were operated at the same center using the same anesthesia, cardiopulmonary bypass, and operation protocols. Data including baseline demographic characteristics and follow-up were retrieved from hospital database. A written informed consent was obtained from each patient. The study protocol was approved by the Kütahya Provincial Health Directorate Ethics Committee (No: 2021/16). The study was conducted in accordance with the principles of the Declaration of Helsinki.

Acute kidney injury was classified in accordance with the Kidney Disease: Improving Global Outcomes (KDIGO) criteria. ${ }^{[10]}$ The patients' final measurement values before surgery were defined as the baseline measurements. The serum creatinine level at $48 \mathrm{~h}$ after surgery was recorded. An increase in baseline creatinine of over $50 \%$ (i.e., $0.3 \mathrm{mg} / \mathrm{dL}$ increase) was defined as Stage 1 AKI, an increase of $\geq 100 \%$ as Stage 2 AKI, and an increase of $\geq 200 \%$ as Stage 3 AKI. None of the patients had Stage 2-3 AKI. The patients having no AKI constituted the AKI-negative group, while the patients diagnosed with Stage 1 AKI constituted the AKI-positive group. The estimated glomerular filtration rate (eGFR) was calculated using the Chronic Kidney Disease Epidemiology Collaboration Equation (CKD-EPI) and the Cockcroft-Gault formula for estimating creatinine clearance $(\mathrm{CrCl}){ }^{[11]}$

Administering red blood cell (RBC) transfusion was decided, when a hematocrit level below 25\% or hemoglobin level below $8 \mathrm{~g} / \mathrm{dL}$ was detected in the perioperative period. Administering a fresh frozen plasma (FFP) transfusion was decided, when the international normalized ratio was above 1.4 or activated clotting time or activated partial thromboplastin time was two-times higher than the baseline value. Administering a platelet transfusion was decided, when a platelet count was below $100\left(10^{3} / \mu \mathrm{L}\right)$ and ongoing hemorrhage or drainage was detected.

The primary outcome measure of the study was AKI as defined in accordance with the KDIGO criteria.

\section{Statistical analysis}

Statistical analysis was performed using the Jamovi version 1.2.27 software (https://www.jamovi.org). The Shapiro-Wilk test, skewness and kurtosis values, histograms, and $\mathrm{Q} / \mathrm{Q}$ plots have been used to identify distribution patterns. Descriptive data were expressed in mean \pm standard deviation (SD) or median (interquartile range [IQR]) for continuous variables and in number and frequency for categorical variables, where applicable. For the nominal variables, the chisquare test was used to compare the groups. As the number of patients with postoperative AKI was less than $30(n=19)$, the Mann-Whitney $U$ test was used to compare the non-parametric data. Multivariate analysis was performed on the variables which were found to be statistically significant in the univariate analysis or that are established risk factors as defined in the literature. A $p$ value of $<0.05$ was considered statistically significant.

\section{RESULTS}

Of all 270 elective diabetic CABG patients included in the study, 19 patients were in the AKI-positive group with Stage 1 AKI, while 251 were in the AKI-negative group. Among the patients, 118 (43.7\%) had hypertension. There was no significant difference in the baseline demographic characteristics of the groups including age, sex, presence/lack of hypertension, chronic pulmonary disease, and 


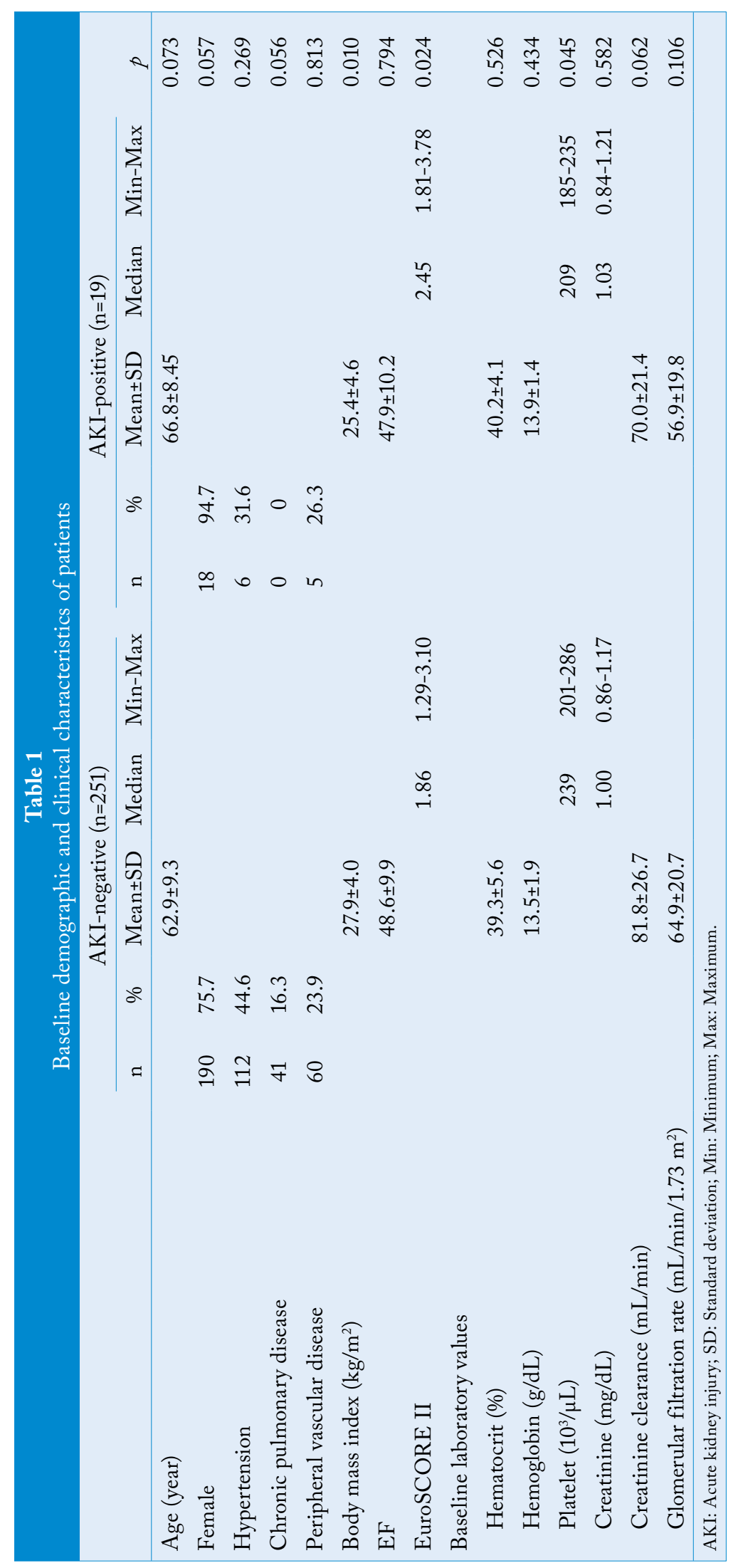




\begin{tabular}{|c|c|c|c|c|c|c|c|}
\hline \multicolumn{8}{|c|}{$\begin{array}{cc}\text { Table } 2 \\
\text { Comparison of patient groups according to postoperative renal mea }\end{array}$} \\
\hline 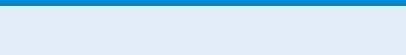 & \multicolumn{3}{|c|}{ AKI-negative $(n=251)$} & \multicolumn{3}{|c|}{ AKI-positive ( $\mathrm{n}=19)$} & \multirow[b]{2}{*}{$p$} \\
\hline & Mean \pm SD & Median & Min-Max & Mean \pm SD & Median & Min-Max & \\
\hline Creatinine (postoperative) & & 1.06 & $0.92-1.23$ & & 1.32 & $1.22-1.54$ & $<0.001$ \\
\hline $\mathrm{CrCl}$ (postoperative) & $70.3 \pm 23.4$ & & & $45.6 \pm 15.0$ & & & $<0.001$ \\
\hline eGFR (postoperative) & $60.1 \pm 19.2$ & & & $39.7 \pm 11.3$ & & & $<0.001$ \\
\hline \multicolumn{8}{|l|}{ Perioperative blood transfusion } \\
\hline RBC (unit) & $1.6 \pm 1.3$ & & & $4.0 \pm 1.3$ & & & $<0.001$ \\
\hline FFP (unit) & $2.8 \pm 1.3$ & & & $4.4 \pm 1.6$ & & & $<0.001$ \\
\hline Platelet (unit) & & 0 & $0-0$ & & 0 & $0-1$ & 0.002 \\
\hline nonRBC (unit) & $3.1 \pm 1.6$ & & & $5.3 \pm 2.3$ & & & $<0.001$ \\
\hline Complete transfusion (unit) & $4.7 \pm 2.5$ & & & $9.2 \pm 3.2$ & & & $<0.001$ \\
\hline
\end{tabular}

peripheral vascular disease; and baseline hematocrit, hemoglobin, and creatinine levels, except for the body mass index, EuroSCORE II, and baseline platelet count (Table 1).

Postoperative renal measurements such as creatinine levels, $\mathrm{CrCl}$, and eGFR revealed statistically significant differences between the groups (Table 2). Of the patients, 41 had no RBC transfusion during the perioperative period; all patients had at least one unit of transfusion (RBC or non-RBC transfusion). The AKI-positive group was found to have higher transfusion rates, including RBC $(p<0.001)$, FFP $(\mathrm{p}<0.001)$, platelet $(\mathrm{p}=0.002)$, and complete $(\mathrm{p}<0.001)$ transfusions. None of the patients had any permanent postoperative renal impairment.
The factors found to be significant in the univariate analysis and the established risk factors described in the literature for AKI were examined (Table 3). For renal impairment, the eGFR was taken into account to represent renal function. No statistically significant relationship was found for age, hypertension, EuroSCORE II, or baseline eGFR with AKI in the logistic regression analysis. Perioperative RBC transfusions, non-RBC transfusions (summation of the FFP and platelet transfusions), and complete transfusions were found to be associated with AKI. The $\mathrm{R}^{2}$ Nagelkerke was greater than $20 \%$ and accuracy exceeded $90 \%$ for all three univariate logistic regression analyses, all of which had values of $\mathrm{p}<.001$.

\begin{tabular}{|c|c|c|c|c|c|}
\hline \multicolumn{6}{|c|}{$\begin{array}{l}\text { Table } 3 \\
\text { Univariate logistic regression analysis results for acute kidney injury }\end{array}$} \\
\hline & Odds ratio & $95 \% \mathrm{CI}$ & $p$ & $\mathrm{R}^{2}$ Nagerkerke & Accuracy \\
\hline Age & 1.050 & $0.995-1.108$ & 0.075 & - & - \\
\hline Hypertension & 0.573 & $0.211-1.555$ & 0.274 & - & - \\
\hline EuroSCORE II & 1.093 & $0.912-1.310$ & 0.336 & - & - \\
\hline Baseline eGFR & 0.981 & $0.958-1.000$ & 0.107 & - & - \\
\hline RBC (unit) & 2.572 & $1.838-3.597$ & $<.001$ & 0.335 & $91.9 \%$ \\
\hline nonRBC (unit) & 1.829 & $1.423-2.352$ & $<.001$ & 0.216 & $93.7 \%$ \\
\hline Complete transfusion (unit) & 1.543 & $1.321-1.802$ & $<.001$ & 0.310 & $93.7 \%$ \\
\hline
\end{tabular}


The receiver operating characteristic (ROC) curve analysis was performed for the statistically significant variables (i.e., RBC, non-RBC, and complete transfusions) to define a cut-off value for each; however, reliable cut-off values could not be obtained due to the limited number of patients in the AKI-positive group. The statistically insignificant results of the ROC analysis are not presented.

\section{DISCUSSION}

Diabetic patients are prone to complications after $\mathrm{CABG}$ surgery, and a special interest and implementations are required during the perioperative period. Diabetic CABG patients are at an increased risk for cerebrovascular disease, AKI, sternal infections, and mortality and require transfusions more often. ${ }^{[12]}$ Diabetes mellitus is an independent risk factor for AKI, even when blood transfusions are not considered. Endothelial dysfunction and impaired microcirculation are considered to be responsible for its pathogenesis. ${ }^{[12,13]}$

Several factors have been found to be associated with increased blood transfusion. According to Klein et al., ${ }^{[14]}$ age, sex, body surface area, logistic EuroSCORE, preoperative hemoglobin and creatinine were associated with increased blood transfusion.

Blood transfusions are a specific topic that may complicate and lead to AKI in CABG patients and requires a rigorous approach. ${ }^{[15]}$ Cardiovascular surgeons tend to avoid redundant blood transfusions, and studies defining the safe limits for blood transfusion have been previously published. ${ }^{[16]}$ Restrictive or liberal thresholds for RBC transfusions were investigated by Mazer et al. ${ }^{[17]}$ The transfusion criteria were defined as a hemoglobin level of $<7.5 \mathrm{mg} / \mathrm{dL}$ for the restrictive threshold approach and a hemoglobin level of $<9.5 \mathrm{mg} / \mathrm{dL}$ for the liberal threshold approach. The study showed the restrictive threshold approach to not be inferior to the liberal threshold approach with respect to mortality, infection, neurological complications, pulmonary impairment, and AKI. The six-month follow-up results of the study also supported the initial results. ${ }^{[18]}$

Lower body mass index, higher logistic EuroSCORE II, and lower preoperative platelet counts in our cohort were found to be associated with Stage 1 AKI. Receiving blood transfusion during the perioperative period was also found to be associated with a higher incidence of Stage 1 AKI in terms of $\mathrm{RBC}, \mathrm{FFP}$, platelet, and complete transfusions.

In their propensity score-matched retrospective study, Kocyigit et al. ${ }^{[19]}$ found receiving blood transfusion not to be associated with new-onset dialysis or discharge creatinine level in diabetic CABG patients. The Koster et al.'s ${ }^{[20,21]}$ studies also found no significant association between blood transfusion and renal impairment in terms of RBC and apheresis platelet concentrates. However, according to Amini et al., ${ }^{[22]} \mathrm{AKI}$ was associated with $\mathrm{RBC}$ transfusions and diabetes, in addition to advanced age, on-pump cardiac surgery, and prolonged mechanical ventilation.

Although blood transfusions have been shown to be associated with negative outcomes, postoperative anemia after CABG surgery is also related to the increased morbidity. ${ }^{[23]}$ To maintain vital functions at the cellular level and avoid anemia induced hypoxia, keeping hemoglobin levels within the safe range, while avoiding unnecessary blood transfusions is essential.

The use of erythropoietin, oral or intravenous iron replacement, and a predeposit autologous donation may help prevent blood transfusions in the preoperative period. During the intraoperative and early postoperative periods, the use of tranexamic acid and cell salvage may be beneficial. Minimal invasive approaches including thoracoscopic, robotic-assisted, or transcatheter techniques are applicable. Endoscopic harvesting of the saphenous vein may also have relevance. ${ }^{[24-26]}$

Our study presents the results from a limited number of patients. This is the main limitation of the study. The Stage 1 AKI-positive group had a low number of patients; as such, propensity score-matching may not be applicable. Variables that may affect renal impairment such as how many years the patient has been diagnosed as diabetic, their insulin use and dosage amounts, glycated hemoglobin (HbA1c) levels, drainage amounts, use of inotropic agents, and presence of an intra-aortic balloon pump were not studied. This is another limitation of our study. The retrospective design of the study is the third limitation. However, a sample of patients from a single cardiac center provides similar surgical and anesthetic management for the entire study group, which relatively strengthens the results of our study.

In conclusion, our study results suggest that perioperative $\mathrm{RBC}$, FFP, platelet, and complete 
transfusions are associated with postoperative AKI among diabetic CABG patients. Further large-scale, prospective, randomized-controlled studies are needed to gain a better understanding of blood transfusionassociated AKI in this population.

\section{Declaration of conflicting interests}

The authors declared no conflicts of interest with respect to the authorship and/or publication of this article.

\section{Funding}

The authors received no financial support for the research and/or authorship of this article.

\section{REFERENCES}

1. Kindzelski BA, Corcoran P, Siegenthaler MP, Horvath KA. Postoperative acute kidney injury following intraoperative blood product transfusions during cardiac surgery. Perfusion 2018;33:62-70.

2. Bastopcu M, Özhan A, Erdoğan SB, Kehlibar T. Factors associated with excessive bleeding following elective on-pump coronary artery bypass grafting. J Card Surg 2021.

3. Yeşilkaya $\mathrm{N}$, Gökalp $\mathrm{O}$, İner $\mathrm{H}$, Beşir $\mathrm{Y}$, Durmaz $\mathrm{H}$, Gökkurt Y, et al. Effects ofsystemic inflammatory response on coronary artery bypass grafting. Cardiovasc Surg Int 2020;7:8-13.

4. Ter Woorst J, Sjatskig J, Soliman-Hamad M, Akca F, Haanschoten M, van Straten A. Evolution of perioperative blood transfusion practice after coronary artery bypass grafting in the past two decades. J Card Surg 2020;35:1220-7.

5. Nah CW, Ti LK, Liu W, Ng RR, Shen L, Chew ST. A clinical score to predict acute kidney injury after cardiac surgery in a Southeast-Asian population. Interact Cardiovasc Thorac Surg 2016;23:757-61.

6. Rasmussen SR, Kandler K, Nielsen RV, Jakobsen PC, Ranucci M, Ravn HB. Association between transfusion of blood products and acute kidney injury following cardiac surgery. Acta Anaesthesiol Scand 2020;64:1397-404.

7. Darby PJ, Kim N, Hare GM, Tsui A, Wang Z, Harrington A, et al. Anemia increases the risk of renal cortical and medullary hypoxia during cardiopulmonary bypass. Perfusion 2013;28:504-11.

8. Hertzberg D, Sartipy U, Holzmann MJ. Type 1 and type 2 diabetes mellitus and risk of acute kidney injury after coronary artery bypass grafting. Am Heart J 2015;170:895-902.

9. Zalewska-Adamiec $\mathrm{M}$, Bachorzewska-Gajewska $\mathrm{H}$, Malyszko J, Tomaszuk-Kazberuk A, Nowak K, Hirnle T, et al. Impact of diabetes on mortality and complications after coronary artery by-pass graft operation in patients with left main coronary artery disease. Adv Med Sci 2014;59:250-5.

10. Khwaja A. KDIGO clinical practice guidelines for acute kidney injury. Nephron Clin Pract 2012;120:c179-84.

11. Fernandez-Prado R, Castillo-Rodriguez E, Velez-Arribas FJ, Gracia-Iguacel C, Ortiz A. Creatinine clearance is not equal to glomerular filtration rate and cockcroft-gault equation is not equal to CKD-EPI collaboration equation. Am J Med 2016;129:1259-63.

12. Zhang X, Wu Z, Peng X, Wu A, Yue Y, Martin J, et al. Prognosis of diabetic patients undergoing coronary artery bypass surgery compared with nondiabetics: A systematic review and meta-analysis. J Cardiothorac Vasc Anesth 2011;25:288-98.

13. Doğan C, Özer T, Aksoy R, Deniz Acar RD, Bayram Z, Adademir T, et al. The effect of time between angiography and coronary artery bypass grafting on postoperative acute kidney injury in patients with diabetes mellitus. Turk Gogus Kalp Dama 2019;27:1-8.

14. Klein AA, Collier T, Yeates J, Miles LF, Fletcher SN, Evans $\mathrm{C}$, et al. The ACTA PORT-score for predicting perioperative risk of blood transfusion for adult cardiac surgery. Br J Anaesth 2017;119:394-401.

15. Bhaskar B, Dulhunty J, Mullany DV, Fraser JF. Impact of blood product transfusion on short and long-term survival after cardiac surgery: more evidence. Ann Thorac Surg 2012;94:460-7.

16. Ming Y, Liu J, Zhang F, Chen C, Zhou L, Du L, et al. Transfusion of red blood cells, fresh frozen plasma, or platelets is associated with mortality and infection after cardiac surgery in a dose-dependent manner. Anesth Analg 2020;130:488-97.

17. Mazer CD, Whitlock RP, Fergusson DA, Hall J, BelleyCote E, Connolly $\mathrm{K}$, et al. Restrictive or liberal redcell transfusion for cardiac surgery. $\mathrm{N}$ Engl J Med 2017;377:2133-44.

18. Mazer CD, Whitlock RP, Fergusson DA, Belley-Cote E, Connolly K, Khanykin B, et al. Six-month outcomes after restrictive or liberal transfusion for cardiac surgery. N Engl J Med 2018;379:1224-33.

19. Koçyiğit M, Ulugöl H, İrem Kıran S, Alhan C, Toraman F. Did blood transfusion increase mortality in patients with diabetes undergoing isolated coronary artery bypass graft surgery? A propensity score-matched analysis of 816 patients. Turk Gogus Kalp Dama 2020;28:586-92.

20. Koster A, Zittermann A, Börgermann J, Knabbe C, Diekmann J, Schirmer U, et al. Transfusion of 1 and 2 units of red blood cells does not increase mortality and organ failure in patients undergoing isolated coronary artery bypass grafting. Eur J Cardiothorac Surg 2016;49:931-6.

21. Koster A, Zittermann A, Birschmann I, Gummert J. Isolated transfusion of leucocyte-depleted apheresis platelet concentrates and outcomes after cardiac surgery. Interact Cardiovasc Thorac Surg 2018;26:155-7.

22. Amini S, Najafi MN, Karrari SP, Mashhadi ME, Mirzaei $S$, Tashnizi MA, et al. Risk factors and outcome of acute kidney injury after isolated CABG surgery: A prospective cohort study. Braz J Cardiovasc Surg 2019;34:70-5.

23. LaPar DJ, Hawkins RB, McMurry TL, Isbell JM, Rich JB, Speir AM, et al. Preoperative anemia versus blood 
transfusion: Which is the culprit for worse outcomes in cardiac surgery? J Thorac Cardiovasc Surg 2018;156:6674.e2.

24. Chambault AL, Brown LJ, Mellor S, Harky A. Outcomes of cardiac surgery in Jehovah's Witness patients: A review. Perfusion 2020:267659120980375.

25. Zimmermann E, Zhu R, Ogami T, Lamonica A, Petrie
JA 3rd, Mack C, et al. Intraoperative autologous blood donation leads to fewer transfusions in cardiac surgery. Ann Thorac Surg 2019;108:1738-44.

26. Ruel M, Shariff MA, Lapierre H, Goyal N, Dennie C, Sadel $\mathrm{SM}$, et al. Results of the minimally invasive coronary artery bypass grafting angiographic patency study. J Thorac Cardiovasc Surg. 2014;147:203-8. 